\title{
Proanthocyanidins Attenuation of $\mathrm{H}_{2} \mathrm{O}_{2}$-Induced Oxidative Damage in Tendon-Derived Stem Cells via Upregulating Nrf-2 Signaling Pathway
}

\author{
Wenshuang Sun, Jia Meng, Zhenheng Wang, Tao Yuan, Hong Qian, Wenxiang Chen, \\ Jian Tong, Yu Xie, Ya Zhang, Jianning Zhao, and Nirong Bao \\ Department of Orthopedics, Nanjing Jinling Hospital, No. 305 Zhongshan East Road, Nanjing 210000, China \\ Correspondence should be addressed to Jianning Zhao; zhaojianning.0207@163.com and Nirong Bao; bnrbnr@sina.com
}

Received 12 June 2017; Revised 13 August 2017; Accepted 27 September 2017; Published 22 October 2017

Academic Editor: Aijun Wang

Copyright (c) 2017 Wenshuang Sun et al. This is an open access article distributed under the Creative Commons Attribution License, which permits unrestricted use, distribution, and reproduction in any medium, provided the original work is properly cited.

Proanthocyanidins (PCs) have shown inhibition of oxidative damage by improving Nrf-2 expression in many tissues. However, the cytoprotective effects of PCs on $\mathrm{H}_{2} \mathrm{O}_{2}$-induced tendon damage have not been verified. The current study was aimed at assessing the cytoprotection of PCs on the oxidative cellular toxicity of tendon-derived stem cells (TDSCs) induced by $\mathrm{H}_{2} \mathrm{O}_{2}$. The TDSCs were isolated from patellar tendons of Sprague Dawley (SD) rats, and the cells after third passage were used for subsequent experiments. The isolated cells were identified by flow cytometry assay and multidifferentiation potential assay. Cell Counting Kit- 8 assay was performed to examine cell viability. Real-Time PCR and Western Blot were employed to, respectively, assess the mRNA and protein expressions of Nrf-2, GCLM, NQO-1, and HO-1. PCs significantly improved the cell viability of TDSCs. Furthermore, $\mathrm{H}_{2} \mathrm{O}_{2}$ upregulated Nrf-2, GCLM, NQO-1, and HO-1 without significant difference, while the proteins expressions were increased with significant difference in PCs group and PCs $+\mathrm{H}_{2} \mathrm{O}_{2}$ cotreated group. All the findings indicated that PCs could protect against the oxidative damage induced by $\mathrm{H}_{2} \mathrm{O}_{2}$ in TDSCs, and the cytoprotective effects might be due to the ability of PCs to activate the expressions of GCLM, HO-1, and NQO-1 via upregulating Nrf-2 signaling pathway.

\section{Introduction}

Tendon injuries are some of the most intractable orthopedic problems. Numberous tendon injuries are chronic and degenerative, which result in the formation of fibrovascular scar that never attain the gross, histological, or mechanical characteristics of normal tendon, as tendon has very little regenerative capacity of its own [1]. In the degenerative process, mitochondrial dysfunction causes an overproduction of reactive oxygen species (ROS) [2], which would result in the oxidative damage. The oxidative stress may play a role in tendon degeneration process, with a constant loss of tendon function [3]. This could be more pronounced in the elderly population in whom age-related physiological dysfunctions could impair antioxidant defenses and increase susceptibility to oxidative stress and tendon damage [4]. Therefore, the oxidative damage is inevitable in tendon degeneration, and the theory of oxidative-stress-related tendon damage has attracted increasing attention.
Nowadays, no effective therapies for tendon injury are available, but cell based therapies are fully addressed [5]. An amount of evidence has demonstrated that tendon-derived stem cells (TDSCs) are multipotent $[6,7]$ and play a major role in the maintenance of tendon homeostasis and recovery after injury [8]. Some studies have indicated that TDSCs effectively promote tendon remodeling in animals tendon injury model $[9,10]$, and they would be better repaired if they were cotreated with platelet-rich plasma [11], BMP-2 (bone morphogenetic protein-2) [12] or ADSCs (Adipose-Derived Stem Cells) [13], and BMSCs (Bone Marrow Mesenchymal Stem Cells) [14]. However, in the process of tendon degeneration, the oxidative damage to TDSCs could not be avoided either, so we brought TDSCs into our cytological study for determining the effect of oxidative damage on TDSCs, in consideration of the potential of TDSCs in tendon repair.

Proanthocyanidins (PCs) are oligomers and polymers of flavan-3-ols which contain various amounts of catechin and epicatechin [15], and are especially extracted from grape seeds 
[16]. PCs possess a variety of biological activities, including antioxidant, antitumor, anti-inflammatory, antiallergic, and antitoxic effects [17]. PCs are also powerful natural antioxidants and efficient free radical scavengers, whose antioxidative ability immensely exceeds vitamins C [18]. Cumulative evidence suggests that PCs possess a biological property against oxidative stress in different organs and tissues. A previous study has revealed that ginkgo PCs can effectively lessen cerebral ischemia/reperfusion injury and protect ischemic brain tissue, and these effects are associated with antioxidant properties [19]. Han et al's research indicated that PCs with half-dose colistin were equivalent to antibiotic treatment and assisted weaned animals in resisting intestinal oxidative stress by increasing diversity and improving balance of gut microbes [20]. Moreover, one study has reported that grape seed PCs (GSP) might potentially prevent hypoxic pulmonary hypertension via antioxidant and antiproliferative mechanisms [21]. Another study has proved that PCs could enhance the ability of liver tissue to protect against oxidative stress via the Nrf2/ARE signaling pathway, resulting in decreasing ER stress and apoptosis of liver tissue [22]. Also, PCs preadministration could activate the expression of Nrf- 2 and decrease the NF- $\kappa \mathrm{B}$ activities, suggesting its inhibitory action in inflammatory response by utilizing NF- $\kappa \mathrm{B}$-dependent pathway. PCs induce the activation of PI3K/Akt pathway which regulates the level of Nrf2-dependent inducible expression of HO-1, Trx, and peroxiredoxin I (PrxI) [17].

However, the protective effects of PCs against oxidative damage have not been clarified in TDSCs, and there is no similar study available. So, this study was undertaken to demonstrate the protection against oxidative damage in TDSCs to check whether PCs would, in part, ameliorate the toxic effect of $\mathrm{H}_{2} \mathrm{O}_{2}$. If PCs show protective effects on TDSCs, dietary PCs would serve as medicine against oxidative damage.

\section{Material and Methods}

2.1. Isolation and Culture of Rat TDSCs. TDSCs were isolated from the patellar tendon of 8-week-old SD rats. All experiments were approved by the Animal Care and Use Committee of Jinling Hospital. A total of four SD rats, weighting about $250 \mathrm{~g}$, were sacrificed by chloral hydrate overdose. The whole patellar tendons were excised from both limbs of the four SD rats. After careful removal of the peritendinous connective tissue, the samples were stored in PBS (sh30256.01B, Hyclone, USA). The tissues were then minced $\left(1 \mathrm{~mm}^{3}\right) ; 100 \mathrm{mg}$ of tissue sample was digested with $3 \mathrm{mg}$ type I collagenase (Sigma, USA) for $2 \mathrm{~h}$ at $37^{\circ} \mathrm{C}$ and passed through a $70 \mu \mathrm{m}$ cell strainer (Biologix, USA) to yield single-cell suspension. The released cells were centrifuged at $1000 \mathrm{rpm}$ for $5 \mathrm{~min}$ and resuspended in growth medium consisting of DMEM/F12 (Hyclone, USA) supplemented with $10 \%$ FBS (Hyclone, USA), $100 \mathrm{U} / \mathrm{ml}$ penicillin, and $100 \mu \mathrm{g} / \mathrm{ml}$ streptomycin (SV30010, Hyclone, USA). The isolated cells were cultured in T25 flasks at $37^{\circ} \mathrm{C}$ with $5 \% \mathrm{CO}_{2}$. After being incubated for $24 \mathrm{~h}$, nonadherent cells were removed by washing with PBS. After a week, the cells were trypsinized as passage $0(\mathrm{P} 0)$. Cells after $\mathrm{P} 3$ were used for subsequent experiments.

2.2. Identification of Stem Cells with Lineage-Specific Markers. The isolated cells were identified by flow cytometry assay with lineage-specific markers, including anti-CD90 (ab33694, Abcam, UK) and anti-CD31 (ab33858; Abcam, UK). Isotype controls (ab91357, ab91356; Abcam, UK) were used for anti-CD90 and anti-CD31, respectively. TDSCs $(5 \times$ $10^{5}$ ) at P3 were incubated with fluorescein-conjugated antirat monoclonal antibodies for $1 \mathrm{~h}$ at $4^{\circ} \mathrm{C}$ and centrifuged at $1000 \mathrm{rpm}$ for $5 \mathrm{~min}$. The stained cells were resuspended in $500 \mu \mathrm{L}$ ice-cold PBS containing 10\% FBS and analyzed by FACs (FACSCalibur, Becton Dickinson) [23].

2.3. Multidifferentiation Potential. The osteogenic, adipogenic, and chondrogenic differentiation potential of TDSCs at P3 were investigated according to Rui et al. [23].

2.3.1. Osteogenic Differentiation Assays. TDSCs were seeded at a density of $4 \times 10^{4}$ cells/well in a 6-well plate and cultured until the cells reached confluence. They were then incubated in complete medium, supplemented with $1 \mathrm{nM}$ dexamethasone, $50 \mathrm{mM}$ ascorbic acid, and $20 \mathrm{mM} \beta$-glycerol phosphate (Sigma-Aldrich) for 3 weeks. For alizarin red staining, the cells were fixed in $70 \%$ ethanol for $10 \mathrm{~min}$ and stained with $0.5 \%$ alizarin red (Sigma-Aldrich) for $30 \mathrm{~min}$.

2.3.2. Adipogenic Differentiation Assays. TDSCs were seeded with the same density as that indicated for the osteogenic assays. The medium was replaced with complete medium, supplemented with $500 \mathrm{nM}$ dexamethasone, $0.5 \mathrm{mM}$ isobutylmethylxanthine, $50 \mathrm{mM}$ indomethacin, and $10 \mathrm{ug} / \mathrm{mL}$ insulin (Sigma-Aldrich). The cells were cultured for 3 weeks for the presence of oil droplets by oil red-O staining. The presence of oil droplets was confirmed by staining the cells with $0.3 \%$ fresh oil red-O solution (Sigma-Aldrich) for $2 \mathrm{~h}$ after fixation with $70 \%$ ethanol for $10 \mathrm{~min}$.

2.3.3. Chondrogenic Differentiation Assays. For chondrogenic differentiation, a pellet culture system was used. About $8 \times 10^{5}$ cells were centrifuged into a pellet at $450 \mathrm{~g}$ for $10 \mathrm{~min}$ in a $15 \mathrm{~mL}$ tube and cultured in chondrogenic medium, which contained low-glucose Dulbecco's modified Eagle's medium (Gibco, Invitrogen Carlsbad, CA), supplemented with $10 \mathrm{ng} / \mathrm{mL}$ transforming growth factor- $\beta 3$ (R\&D Systems), $500 \mathrm{ng} / \mathrm{mL}$ bone morphogenetic protein-2 (R\&D Systems), $10^{-7} \mathrm{M}$ dexamethasone, $50 \mathrm{ug} / \mathrm{mL}$ ascorbate2-phosphate, $40 \mathrm{ug} / \mathrm{mL}$ proline, $100 \mathrm{ug} / \mathrm{mL}$ pyruvate (SigmaAldrich), and 1:100 diluted ITS + Premix $(6.25 \mathrm{mg} / \mathrm{mL}$ insulin, $6.25 \mathrm{mg} / \mathrm{mL}$ transferrin, $6.25 \mathrm{mg} / \mathrm{mL}$ selenous acid, $1.25 \mathrm{mg} / \mathrm{mL}$ bovine serum albumin, and $5.35 \mathrm{mg} / \mathrm{mL}$ linoleic acid) (Becton Dickinson, Franklin Lakes, NJ). After 3 weeks, the pellet was fixed for staining of Alcian blue.

2.4. Cell Viability Assessment by the CCK-8 Assay. After trypsinization, P3 TDSCs were seeded at a density of $1 \times 10^{5}$ cells/well in 96-well plates with $100 \mu \mathrm{L}$ complete medium and incubated for $24 \mathrm{~h}$ for subsequent experiments. 
2.4.1. PCs and $\mathrm{H}_{2} \mathrm{O}_{2}$ Cytotoxicity Analysis. Seeded TDSCs were treated with different concentrations of PCs and $\mathrm{H}_{2} \mathrm{O}_{2}$ (PCs, $10-130 \mu \mathrm{g} / \mathrm{mL} ; \mathrm{H}_{2} \mathrm{O}_{2}, 200-500 \mathrm{umol} / \mathrm{mL}$ ) for $2 \mathrm{~h}$ to assess cytotoxic effects. Treatment with $10 \mu \mathrm{L}$ CCK-8 (C0038, Biyuntian, China) per well for $2 \mathrm{~h}$ was performed. Conversion of WST to formazan was measured at $450 \mathrm{~nm}$ on a microplate spectrophotometer (51119200, Thermo Scientific Multiskan, USA). Cytotoxicity assay for PCs was to rule out their cytotoxic effects on TDSCs, while that of $\mathrm{H}_{2} \mathrm{O}_{2}$ was to assess the $\mathrm{IC}_{50}$ value for subsequent studies.

2.4.2. Antioxidant Test of PCs. The cytoprotective effects of PCs on $\mathrm{H}_{2} \mathrm{O}_{2}$-induced oxidative stress were determined. TDSCs were pretreated with PCs at concentrations of 0,10 , 50 , and $90 \mu \mathrm{g} / \mathrm{mL}$ for $2 \mathrm{~h}$ followed by $\mathrm{H}_{2} \mathrm{O}_{2}$ treatment for $2 \mathrm{~h}$. Treatment groups for subsequent experiments were as follows: group I, control; group II, $\mathrm{H}_{2} \mathrm{O}_{2}$ (at $\mathrm{IC}_{50}$ ); group III, PCs $(10 \mu \mathrm{g} / \mathrm{mL})+\mathrm{H}_{2} \mathrm{O}_{2}\left(\mathrm{IC}_{50}\right)$; group IV, PCs $(50 \mu \mathrm{g} / \mathrm{mL})+$ $\mathrm{H}_{2} \mathrm{O}_{2}\left(\mathrm{IC}_{50}\right)$; group V, PCs $(90 \mu \mathrm{g} / \mathrm{mL})+\mathrm{H}_{2} \mathrm{O}_{2}\left(\mathrm{IC}_{50}\right)$.

2.5. Real-Time PCR. Gene expression in TDSCs was assessed by Real-Time PCR. TDSCs were seeded in 6-well plates at a density of $1 \times 10^{5}$ in growth medium. After $24 \mathrm{~h}$, the cells were treated with $100 \mu \mathrm{g} / \mathrm{mL}$ PCs or $200 \mu \mathrm{mol} / \mathrm{mL}$ $\mathrm{H}_{2} \mathrm{O}_{2}$ or treated with both one by one. After incubation for $24 \mathrm{~h}$, total RNA was extracted from the TDSCs using RNA Extraction Kit (No. 9767, TAKARA, Japan). First-strand cDNA was synthesized in a $10 \mu \mathrm{L}$ reaction from $500 \mathrm{ng}$ total RNA by reverse transcription with PrimeScript RT Master Mix (number RR036A, TAKARA, Japan). The Real-Time PCR program for cDNA synthesis was as follows: $37^{\circ} \mathrm{C}$ for $15 \mathrm{~min}$ followed by $85^{\circ} \mathrm{C}$ for $5 \mathrm{~s}$, with a hold at $4^{\circ} \mathrm{C}$. RT-PCR was carried out by using SYBR Premix Ex Taq II (TIi RNaseH Plus) (number RR820A, TAKARA, Japan). The assessed genes were Nrf-2 (nuclear factor erythroidderived factor 2-related factor), GCLM (glutamate-cysteine ligase regulatory subunit), HO-1 (hemoxygenase-1), NQO1 (NADPH: quinone oxidoreductase), and GAPDH (used as an internal control). Forward and reverse primers were synthesized by GenePharma (Shanghai, China) and listed in Table 1. After initial denaturalization for $30 \mathrm{~s}$ at $95^{\circ} \mathrm{C}$, PCR was performed for 40 cycles of denaturalization for $5 \mathrm{~s}$ at $95^{\circ} \mathrm{C}$ and annealing for $34 \mathrm{~s}$ at $60^{\circ} \mathrm{C}$. At least three independent experiments were performed to obtain the relative expression levels for each gene.

2.6. Western Blot. TDSCs were treated with $\mathrm{H}_{2} \mathrm{O}_{2}$ or pretreated with PCs for $24 \mathrm{~h}$ as for Real-Time PCR. Afterward, TDSCs were washed with PBS, lysed in lysis buffer, and kept on ice for $5 \mathrm{~min}$ by Whole Protein Extract Kit (Jiancheng Bioengineering, Nanjing). Cell lysates were centrifuged at $20,000 \mathrm{rpm}$ at $4^{\circ} \mathrm{C}$ for $5 \mathrm{~min}$, and the supernatants were stored at $-80^{\circ} \mathrm{C}$ until use. Protein concentrations were measured by using a protein assay kit (Jiancheng Bioengineering, Nanjing). Twenty micrograms of total protein were diluted in loading buffer, separated by SDS/PAGE, and electroblotted onto PVDF membranes. The membranes were then blocked with TBS-Tween 20 solution containing 5\% nonfat dry milk and incubated overnight at $4^{\circ} \mathrm{C}$ with specific
TABle 1: Primers for Real-Time PCR.

\begin{tabular}{|c|c|c|c|}
\hline Gene & Type & Primers & Size \\
\hline \multirow{2}{*}{ Nrf-2 } & $\mathrm{F}$ & 5'-GGACATGGAGCAAGTTTGGC-3' $^{\prime}$ & \multirow{2}{*}{102} \\
\hline & $\mathrm{R}$ & $5^{\prime}$-GGGCTGGGGACAGTGGTAGT-3' & \\
\hline \multirow{2}{*}{ GCLM } & $\mathrm{F}$ & 5'-ATCATGGCTTCCCСТCCAAT-3' & \multirow{2}{*}{70} \\
\hline & $\mathrm{R}$ & $5^{\prime}$-CCTCCCAGTAAGGCTGCA & \\
\hline \multirow{2}{*}{ NQO-1 } & $\mathrm{F}$ & 5'-CGGTGAGAAGAGCCCTGAT-3' & \multirow{2}{*}{111} \\
\hline & $\mathrm{R}$ & 5'-CGACCACСТCCСАTCСТT-3' & \\
\hline \multirow{2}{*}{$\mathrm{HO}-1$} & $\mathrm{~F}$ & $5^{\prime}$-TCACCTTCCCGAGCATCGA-3' & \multirow{2}{*}{119} \\
\hline & $\mathrm{R}$ & $5^{\prime}$-GGCGGTCTTAGCCTCTTCTGT-3' & \\
\hline \multirow{2}{*}{ GAPDH } & $\mathrm{F}$ & $5^{\prime}$-AGGTCGGTGTGAACGGATTTG-3' & \multirow{2}{*}{95} \\
\hline & $\mathrm{R}$ & 5'-GGGGTCGTTGATGGCAACA-3' & \\
\hline
\end{tabular}

antibodies against Nrf-2 (1:200) (ab31163, Abcam, USA), GCLM (1:1000) (ab126704, Abcam, USA), HO-1 (1:200) (ab68477, Abcam, USA), and $\beta$-actin (ab8226, Abcam, USA). Proteins were visualized using goat anti-rabbit conjugated to HRP and a Chemiluminescence Western Blotting Detection system (34079, Thermo Pierce, USA). Protein band intensities were quantified using the Quantity One software.

2.7. Statistical Analysis. All calculations and statistical analyses were performed with SPSS (V19.0) and GraphPad (V6.0). Values were expressed as mean $\pm \mathrm{SD}$ and analyzed by oneway analysis of variance (ANOVA). $p<0.05$ was considered statistically significant.

\section{Results}

\subsection{Isolation and Identification of TDSCs}

3.1.1. Cell Morphology of TDSCs at Different Passages. TDSCs were heterogeneous in size and density, while reflecting some differences in cell morphology and proliferation. At P0, TDSCs looked like large polygonal and star-shaped cells. At P3, a homogeneous population of fibroblast-like cells was obtained. TDSCs proliferated slowly at P0; however, they grew much faster at $\mathrm{P} 3$ and overspread the cell culture flask at day 3 (Figure 1).

3.1.2. Flow Cytometric Analysis of MSC Markers. To confirm that the obtained TDSCs were stem cells, the expression levels of MSC surface markers were determined, including CD90 and CD31, by flow cytometric analysis. The results showed that $96.8 \%$ of the TDSCs were positive for the fibroblastic marker CD90 and negative for the endothelial cell marker CD31, as compared to the isotype controls (Figure 2(a)).

\subsubsection{Multidifferentiation Potential of TDSCs Colonies}

Osteogenic Differentiation Assays. The osteogenic differentiation potential of the TDSCs colonies was determined and alizarin-red-positive calcium nodules were observed after osteogenic induction of the cells for 3 weeks (Figure 2(b)). 

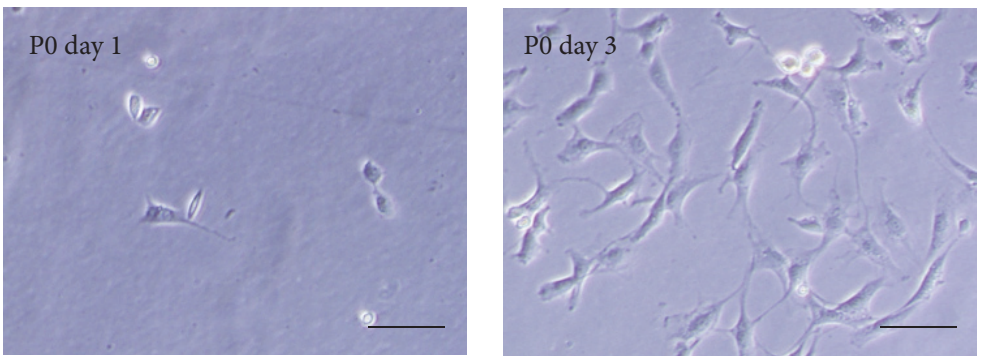

(a)

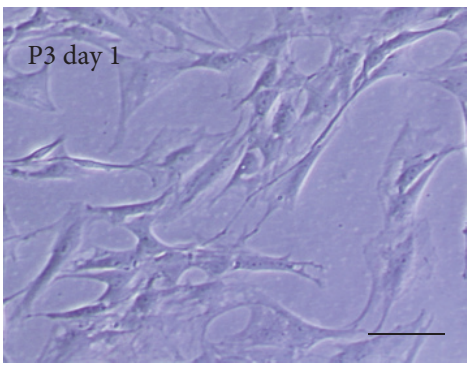

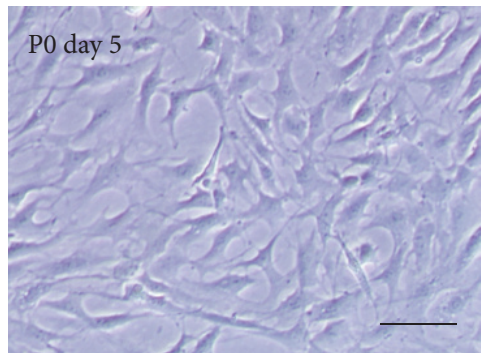

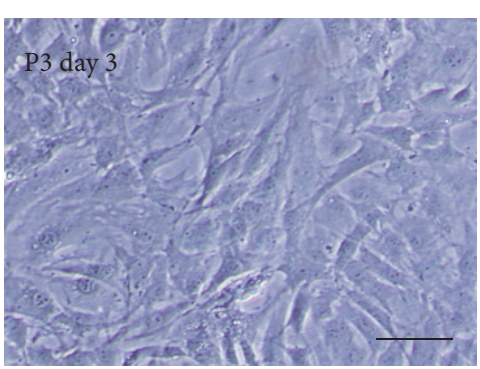

(b)

FIGURE 1: TDSCs culture and characterization. Photomicrographs showed the TDSCs morphology at different passages. (a) At P0, TDSCs looked like large polygonal and star-shaped cells. (b) At P3, a homogeneous population of fibroblast-like cells was obtained. Magnification: $\times 100$. Cell size bar: 100 um.
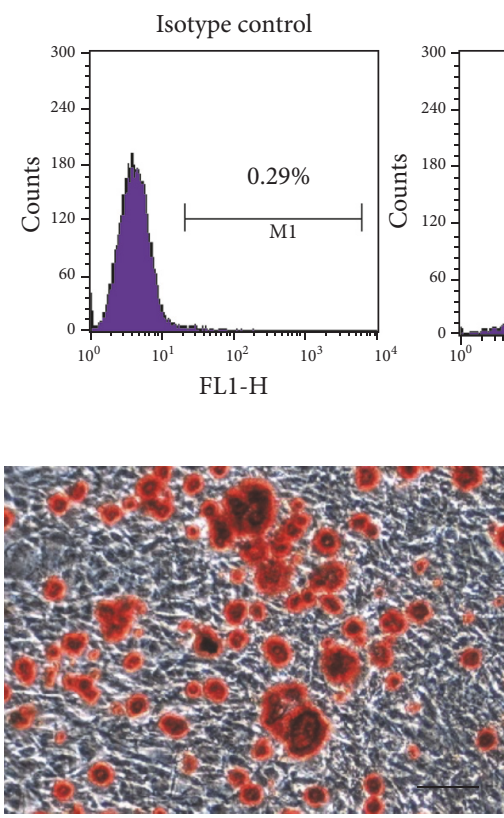

(b)
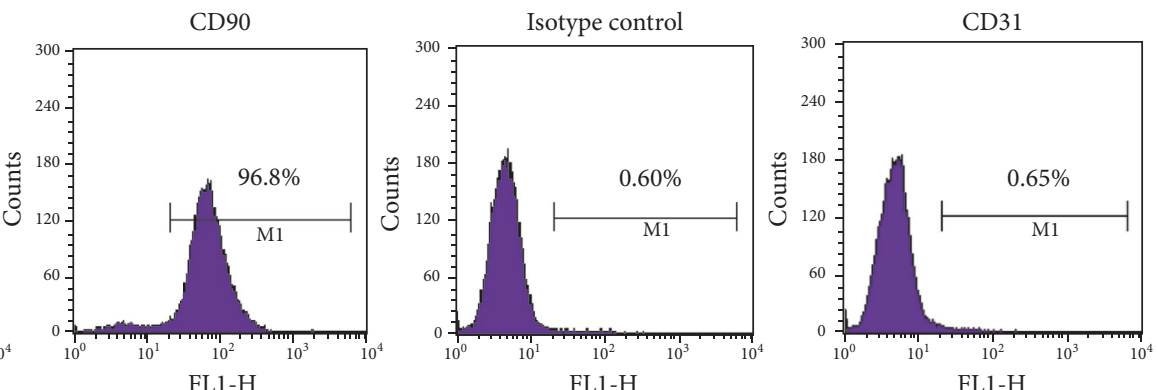

(a)

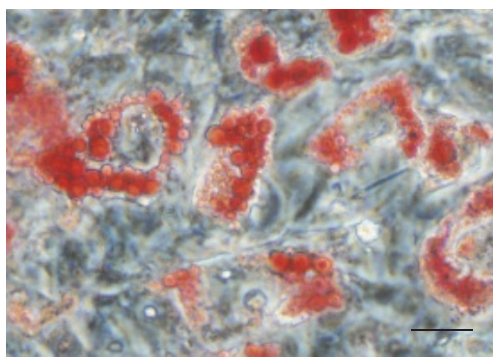

(c)

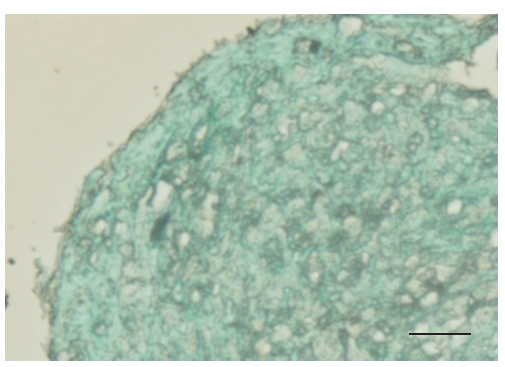

(d)

FIGURE 2: The isolated cells were identified by flow cytometry assay with lineage-specific markers and multidifferentiation potential assays. (a) Graphs showed the expression levels of the mesenchymal stem (CD90) and endothelial (CD31) cell markers on TDSCs. Compared to the isotype control, a high percentage of cells expressed CD90, whereas only few cells showed CD31. (b) Osteogenic differentiation assays. Alizarin-red-positive calcium nodules were observed after osteogenic induction of the cells for 3 weeks. Magnification: $\times 100$. Cell size bar: $100 \mathrm{um}$. (c) Adipogenic differentiation assays. Lipid droplets were formed after incubating the cells in complete medium with adipogenic supplements for 3 weeks. Magnification: $\times 400$. Cell size bar: $25 \mathrm{um}$. (d) Chondrogenic differentiation assays. Cartilage-like tissues with Alcian blue stained acid glycosaminoglycan were observed, which indicated the formation of extracellular cartilage matrix. Magnification: $\times 100$. Cell size bar: 100 um. 


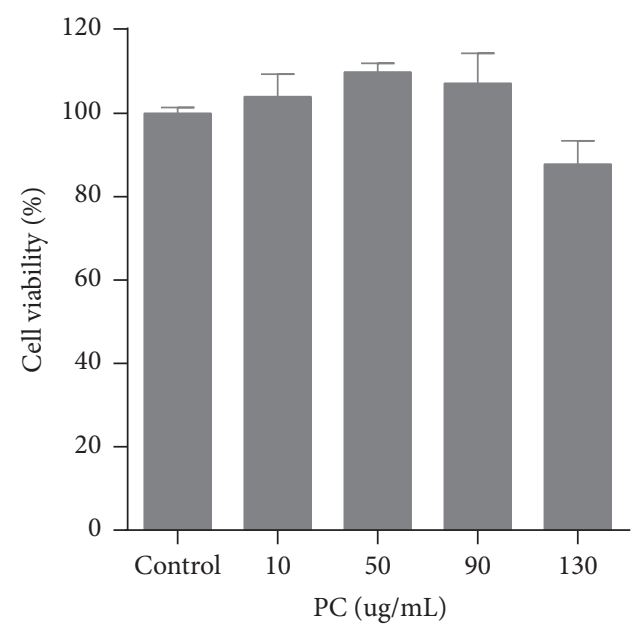

(a)

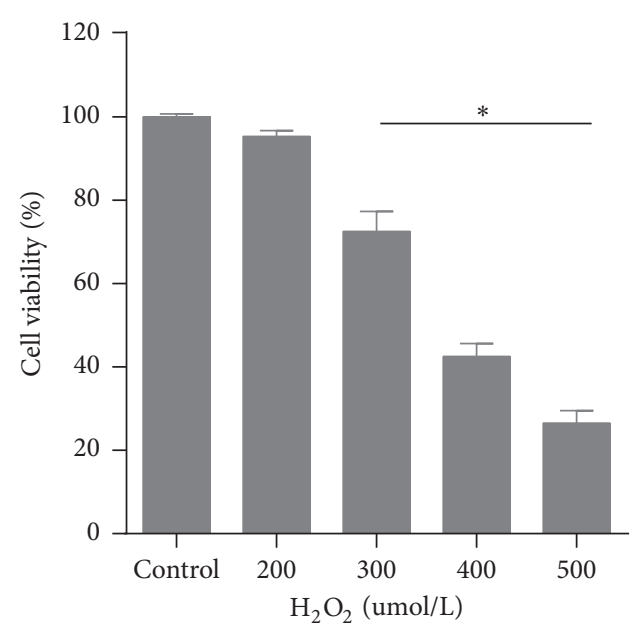

(b)

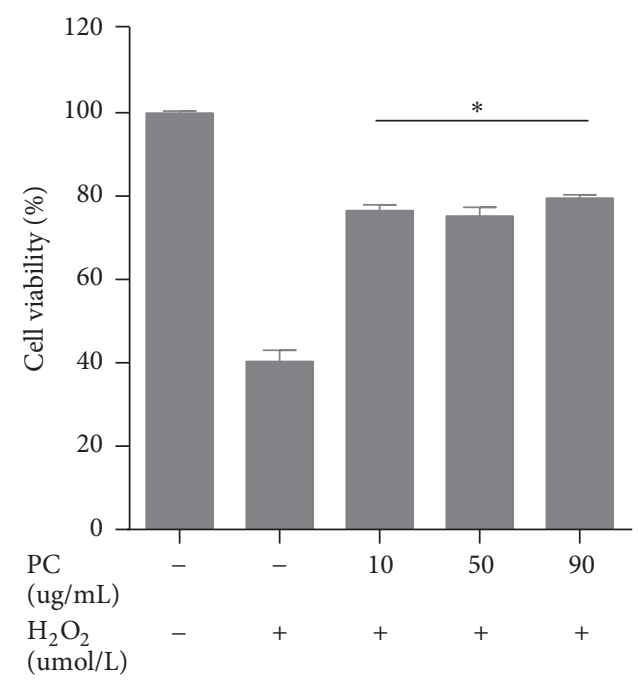

(c)

Figure 3: PCs reduced $\mathrm{H}_{2} \mathrm{O}_{2}$-induced oxidative stress in TDSCs. (a) PCs had no cytotoxic effects on TDSCs $(p>0.05)$. (b) $\mathrm{H}_{2} \mathrm{O}_{2}$ reduced cell viability (\%) in TDSCs; data are percentage of cell viability in comparison to the control group, and viability in the $400 \mu \mathrm{mol} / \mathrm{ml}$ was approximately 50\%, reflecting IC50. (c) PCs protected TDSCs against $\mathrm{H}_{2} \mathrm{O}_{2}$-induced oxidative stress. Obvious differences were observed between the non-PCs and pre-PCs treatment groups, but no significant differences were found among groups pretreated with PCs at various concentrations. $\mathrm{H}_{2} \mathrm{O}_{2}(+): 400 \mu \mathrm{mol} / \mathrm{ml}$. All results were expressed as the mean $\pm \mathrm{SD}(n=3) ;{ }^{*} p<0.05$, as compared to control group.

Adipogenic Differentiation Assays. Lipid droplets were formed after incubating the cells in complete medium with adipogenic supplements for 3 weeks (Figure 2(c)).

Chondrogenic Differentiation Assays. After chondrogenic induction of TDSCs for 3 weeks, cartilage-like tissues with Alcian blue stained acid glycosaminoglycan were observed, which indicated the formation of extracellular cartilage matrix (Figure 2(d)).

According to cell morphology, flow cytometric analysis of MSC markers, and multidifferentiation potential assays, we confirmed that the isolated cells were TDSCs, ruling out contamination by other cells.

3.2. The Cytotoxic Effects of PCs and $\mathrm{H}_{2} \mathrm{O}_{2}$ on TDSCs. Before using PCs and $\mathrm{H}_{2} \mathrm{O}_{2}$ for TDSCs treatment, we assessed their cytotoxicity to rule out PCs cytotoxicity and determine the $\mathrm{IC}_{50}$ value of $\mathrm{H}_{2} \mathrm{O}_{2}$. All PCs amounts showed no cytotoxicity on TDSCs $(p>0.05)$. Meanwhile, the cells treated with $\mathrm{H}_{2} \mathrm{O}_{2}$ at high concentrations were overtly inhibited; the cell viability (\%) obtained with $400 \mu \mathrm{mol} / \mathrm{ml}$ was approximately $50 \%$, and this concentration was considered the $\mathrm{IC}_{50}$ for subsequent experiments. Cytoprotection was achieved by pretreatment with PCs $(p<0.01)$, with a maximum $(p<0.001)$ at $90 \mu \mathrm{g} / \mathrm{ml}$. For the convenience of sample preparation, $100 \mu \mathrm{g} / \mathrm{ml}$ pretreatment was used for determining oxidative stress caused by $\mathrm{H}_{2} \mathrm{O}_{2}$ (Figure 3 ).

3.3. The Effects of PCs on $\mathrm{H}_{2} \mathrm{O}_{2}$-Induced Alteration of $\mathrm{Nrf}$ 2, GCLM, HO-1, and NQO-1 Expression Levels. To evaluate whether Nrf-2 activation played a role in PCs protection against the oxidative damage induced by $\mathrm{H}_{2} \mathrm{O}_{2}$, the 

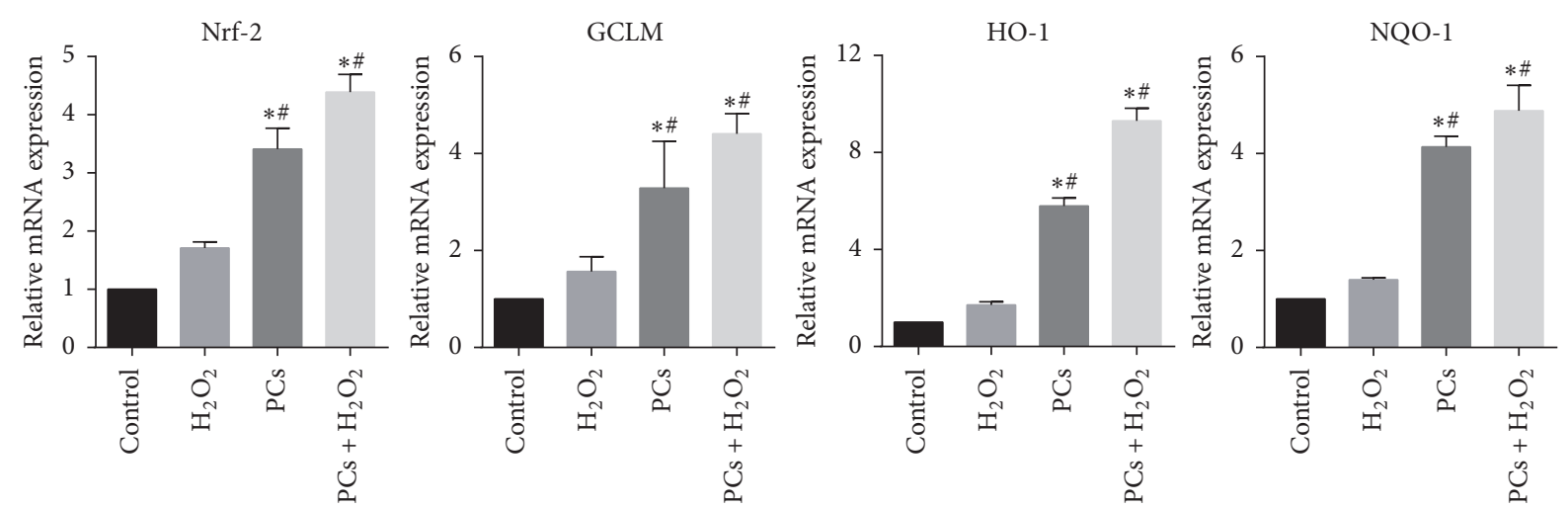

(a)
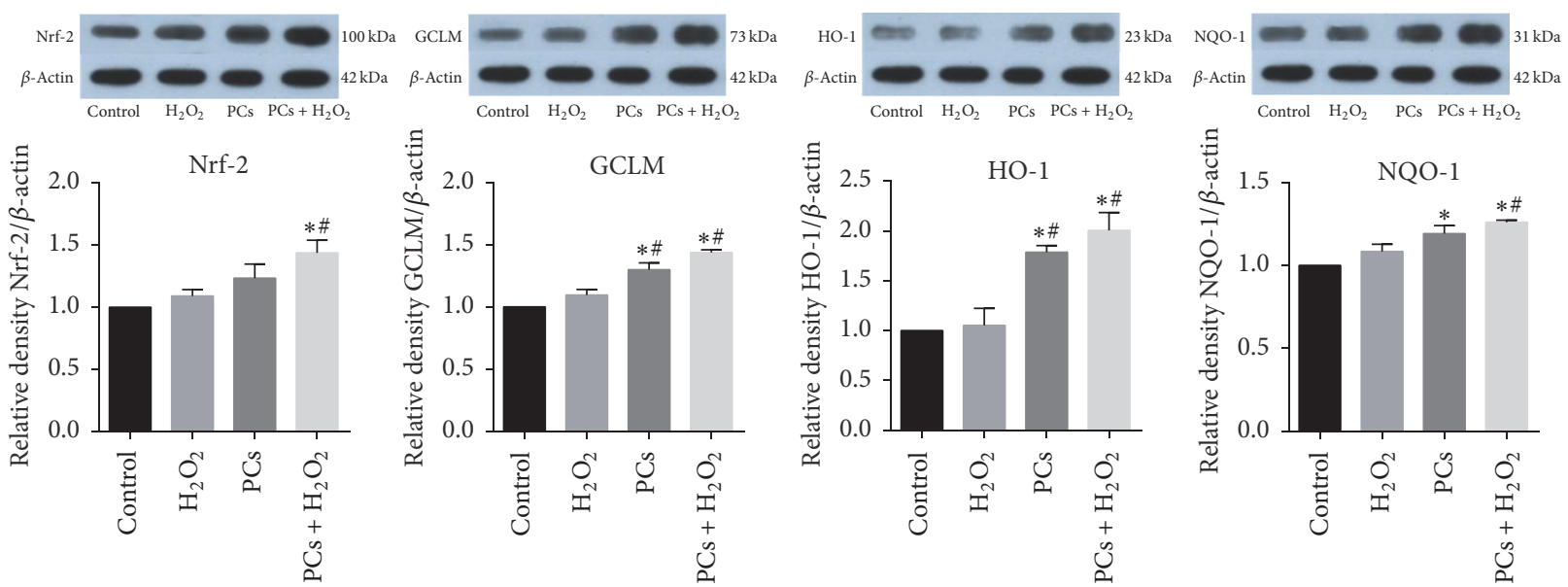

(b)

Figure 4: The effects of PCs on $\mathrm{H}_{2} \mathrm{O}_{2}$-induced alterations of Nrf-2, GCLM, HO-1, and NQO-1 mRNA and protein levels. (a) The effects of PCs on alterations of mRNA levels. (b) The effects of PCs on alterations of protein levels. All results were expressed as the mean \pm SD $(n=3)$; ${ }^{*} p<0.05$, as compared to control group; ${ }^{*} p<0.05$, as compared to $\mathrm{H}_{2} \mathrm{O}_{2}$ group.

expression of Nrf-2 and its downstream genes including GCLM, HO-1, and NQO-1 in TDSCs was measured. As shown in Figure 4(a), the Real-Time PCR results showed that mRNA expression levels of Nrf-2 and its downstream genes in the $\mathrm{H}_{2} \mathrm{O}_{2}$ group were increased without significant difference $(p>0.05)$, while expressions of these genes were increased with significant difference in the PCs group and $\mathrm{PCs} / \mathrm{H}_{2} \mathrm{O}_{2}$ cotreated group $(p<0.05)$ compared with the control group. The expressions of Nrf-2 and its downstream genes in the PCs group and $\mathrm{PCs} / \mathrm{H}_{2} \mathrm{O}_{2}$ cotreated group were significantly increased $(p<0.05)$ compared with the $\mathrm{H}_{2} \mathrm{O}_{2}$ group. Meanwhile, as shown in Figure 4(b), the Western Blot results presented the same feature $(p<0.05)$, except Nrf-2 and NQO-1 in PCs group $(p>0.05)$.

\section{Discussion}

The current study demonstrated that PCs had cytoprotective effects on oxidative cytotoxicity to TDSCs. These effects were achieved via upregulating $\mathrm{Nrf}-2$ signaling pathway. Our results indicated that the oxidative stress induced by $\mathrm{H}_{2} \mathrm{O}_{2}$ indeed caused the oxidative damage, and the efficient antioxidant effects of PCs were also available in TDSCs.
PCs are extremely efficient natural antioxidants, their antioxidant activity is 20 times higher than that of vitamin $\mathrm{C}$, and the antioxidant effects have been revealed in a range of studies. According to the cytotoxicity analyses by CCK8 assay, it was shown that PCs had no cytotoxic effects on TDSCs, and they did not influence the cell viability of TDSCs. The cell viability of TDSCs treated with $\mathrm{H}_{2} \mathrm{O}_{2}$ was obviously decreased, resulting from the $\mathrm{H}_{2} \mathrm{O}_{2}$-induced oxidative damage. However, the cell viability of TDSCs pretreated with PCs was distinctly improved, even at a very low concentration, and this exhibited the efficient antioxidant effects of PCs on TDSCs.

Currently, Nrf-2 is the key molecule which mediates the response of the endogenous antioxidant system. Under basal homoeostatic redox conditions, Nrf-2 is blocked in the cytoplasm by Keap-1 via one high-affinity site and one low-affinity binding site [24]. In response to both oxidative and electrophilic stressors, the Keap-1/Nrf-2 interaction is disrupted, allowing Nrf-2 to translocate to the nucleus and activate downstream genes. Previous studies have suggested that Nrf-2 plays a crucial role in cellular resistance to oxidative and exogenous damage $[25,26]$, and activation of Nrf-2 can improve the expression of antioxidant genes and 
induce synthesis of phase II detoxifying enzymes [27]. The Nrf-2/ARE pathway is also capable of stimulating the activity of superoxide dismutase (SOD), hemoxygenase-1 (HO-1), NADPH: quinone oxidoreductase (NQO1), and glutamatecysteine ligase regulatory subunit (GCLM) [28].

In our study, the results showed that the gene transcription level of Nrf-2 was increased in the $\mathrm{H}_{2} \mathrm{O}_{2}$ group. This result indicated that, in order to cope with the oxidative damage induced by $\mathrm{H}_{2} \mathrm{O}_{2}$, the TDSCs activated Nrf-2 signaling pathway to compensate for the oxidative damage [25-27]. When the TDSCs were treated with PCs, the Nrf-2 mRNA and protein expressions were also elevated with a significant difference compared with control group and $\mathrm{H}_{2} \mathrm{O}_{2}$ group. This result indicated that PCs could activate the expression of Nrf-2, and the protective effect was related to Nrf-2 signaling pathway. Previous studies have demonstrated that the activation of $\mathrm{Nrf}-2$ could improve the expression of antioxidant genes, including GCLM, NQO-1, and HO-1 [28]. Our results showed that PCs could upregulate Nrf-2 downstream gene GCLM, NQO-1, and HO-1 expression, resulting in enhancing the ability of TDSCs to resist the oxidative damage induced by $\mathrm{H}_{2} \mathrm{O}_{2}$. Combined with our previous results, the cell viability was significantly improved in the group cotreated with PCs, resulting from the upregulation of these genes via Nrf2 signaling pathway. Although our study had proved the efficient antioxidant effects of PCs on TDSCs, the molecular mechanism responsible for the activation of Nrf-2 was not clarified and was worthy of further investigation.

The study had provided evidence that PCs had efficient antioxidant effects on TDSCs, and our results suggested that PCs protected TDSCs against oxidative damage via Nrf2 signaling pathway. These findings may be attributed to the manifold effects of PCs as functional foods in future application.

\section{Conclusion}

In conclusion, our study indicated that PCs could protect against the oxidative damage induced by $\mathrm{H}_{2} \mathrm{O}_{2}$ in TDSCs, and the cytoprotective effects might be achieved by the fact that PCs activated the expression of GCLM, HO-1, and NQO-1 via upregulating Nrf-2 signaling pathway.

\section{Disclosure}

Wenshuang Sun and Jia Meng are co-first authors.

\section{Conflicts of Interest}

The authors declare that there are no conflicts of interest regarding the publication of this paper.

\section{Authors' Contributions}

Conception and design of experiments were done by Wenshuang Sun, Jianning Zhao, and Nirong Bao, experiments were performed by Wenshuang Sun, Hong Qian, Jian Tong, and Wenxiang Chen. Data analysis was done by Zhenheng
Wang, Tao Yuan, Yu Xie, and Ya Zhang. Wenshuang Sun and Jia Meng wrote the paper.

\section{Acknowledgments}

The authors would like to express their sincere appreciation to the professors of the Department of Orthopedics, Nanjing Jinling Hospital, for providing their valuable advice. The study was supported by the Project of Invigorating Health Care through Science, Technology and Education (QNRC2016914).

\section{References}

[1] L. M. Galatz, L. Gerstenfeld, E. Heber-Katz, and S. A. Rodeo, "Tendon regeneration and scar formation: The concept of scarless healing," Journal of Orthopaedic Research, vol. 33, no. 6, pp. 823-831, 2015.

[2] C. H. Wang, S. B. Wu, and Y. T. Wu, "Oxidative stress response elicited by mitochondrial dysfunction: implication in the pathophysiology of aging," Experimental Biology Medicine, vol. 238, no. 5, p. 450, 2013.

[3] E. Marzetti, R. Calvani, M. Cesari et al., "Mitochondrial dysfunction and sarcopenia of aging: from signaling pathways to clinical trials," International Journal of Biochemistry \& Cell Biology, vol. 45, no. 10, pp. 2288-2301, 2013.

[4] S. A. Guaraldo, A. J. Serra, E. M. Amadio et al., "The effect of low-level laser therapy on oxidative stress and functional fitness in aged rats subjected to swimming: an aerobic exercise," Lasers in Medical Science, vol. 31, no. 5, pp. 833-840, 2016.

[5] H.-S. Chen, Y.-L. Chen, H.-J. Harn, J.-S. Lin, and S.-Z. Lin, "Stem cell therapy for tendon injury," Cell Transplantation, vol. 22, no. 4, pp. 677-684, 2013.

[6] Y. Bi, D. Ehirchiou, T. M. Kilts et al., "Identification of tendon stem/progenitor cells and the role of the extracellular matrix in their niche," Nature Medicine, vol. 13, no. 10, pp. 1219-1227, 2007.

[7] J. Zhang and J. H.-C. Wang, "Characterization of differential properties of rabbit tendon stem cells and tenocytes," $B M C$ Musculoskeletal Disorders, vol. 11, article 10, 2010.

[8] J. Zhang, J. H. Wang, and R. K. Roeder, "The effects of mechanical loading on tendons - an in vivo and in vitro model study," PLoS ONE, vol. 8, no. 8, Article ID e71740, 2013.

[9] I. Komatsu, J. H.-C. Wang, K. Iwasaki, T. Shimizu, and T. Okano, "The effect of tendon stem/progenitor cell (TSC) sheet on the early tendon healing in a rat Achilles tendon injury model," Acta Biomaterialia, vol. 42, pp. 136-146, 2016.

[10] M. Ni, P. P. Y. Lui, Y. F. Rui et al., “Tendon-derived stem cells (TDSCs) promote tendon repair in a rat patellar tendon window defect model," Journal of Orthopaedic Research, vol. 30, no. 4, pp. 613-619, 2012.

[11] L. Chen, J. P. Liu, K. L. Tang et al., “Tendon derived stem cells promote platelet-rich plasma healing in collagenase-induced rat achilles tendinopathy," Cellular Physiology and Biochemistry International Journal of Experimental Cellular Physiology Biochemistry and Pharmacology, vol. 34, no. 6, pp. 2153-2168, 2014.

[12] Y. F. Rui, P. P. Y. Lui, M. Ni, L. S. Chan, Y. W. Lee, and K. M. Chan, "Mechanical loading increased BMP-2 expression which promoted osteogenic differentiation of tendon-derived stem cells," Journal of Orthopaedic Research, vol. 29, no. 3, pp. 390396, 2011. 
[13] J. H. Oh, S. W. Chung, S. H. Kim, J. Y. Chung, and J. Y. Kim, "2013 Neer Award: Effect of the adipose-derived stem cell for the improvement of fatty degeneration and rotator cuff healing in rabbit model," Journal of Shoulder and Elbow Surgery, vol. 23, no. 4, pp. 445-455, 2014.

[14] T. Wu, Y. Liu, B. Wang et al., "The use of cocultured mesenchymal stem cells with tendon-derived stem cells as a better cell source for tendon repair," Tissue Engineering Part: A, vol. 22, no. 19-20, pp. 1229-1240, 2016.

[15] C. S. Malisch, A. Lüscher, N. Baert et al., "Large Variability of Proanthocyanidin Content and Composition in Sainfoin (Onobrychis viciifolia)," Journal of Agricultural and Food Chemistry, vol. 63, no. 47, pp. 10234-10242, 2015.

[16] M. Nassiri-Asl and H. Hosseinzadeh, "Review of the pharmacological effects of Vitis vinifera (grape) and its bioactive compounds," Phytotherapy Research, vol. 23, pp. 1197-1204, 2009.

[17] N. Bashir, V. Manoharan, and S. Miltonprabu, "Grape seed proanthocyanidins protects against cadmium induced oxidative pancreatitis in rats by attenuating oxidative stress, inflammation and apoptosis via Nrf-2/HO-1 signaling," The Journal of Nutritional Biochemistry, vol. 32, pp. 128-141, 2016.

[18] D. Bagchi, A. Garg, and R. L. Krohn, "Oxygen free radical scavenging abilities of vitamins $\mathrm{C}$ and $\mathrm{E}$, and a grape seed proanthocyanidin extract in vitro," Research Communications in Molecular Pathology Pharmacology, vol. 95, no. 2, p. 179, 1997.

[19] W.-L. Cao, H.-B. Huang, L. Fang, J.-N. Hu, Z.-M. Jin, and R.-W. Wang, "Protective effect of ginkgo proanthocyanidins against cerebral ischemia/reperfusion injury associated with its antioxidant effects," Neural Regeneration Research, vol. 11, no. 11, pp. 1779-1783, 2016.

[20] M. Han, P. Song, C. Huang et al., "Dietary grape seed proanthocyanidins (GSPs) improve weaned intestinal microbiota and mucosal barrier using a piglet model," Oncotarget , vol. 7, no. 49, pp. 80313-80326, 2016.

[21] H. Jin, M. Liu, X. Zhang et al., "Grape seed procyanidin extract attenuates hypoxic pulmonary hypertension by inhibiting oxidative stress and pulmonary arterial smooth muscle cells proliferation," The Journal of Nutritional Biochemistry, vol. 36, pp. 81-88, 2016.

[22] M. Long, Y. Liu, Y. Cao, N. Wang, M. Dang, and J. He, "Proanthocyanidins attenuation of chronic lead-induced liver oxidative damage in kunming mice via the Nrf2/ARE pathway," Nutrients, vol. 8, no. 10, article no. 656, 2016.

[23] Y.-F. Rui, P. P. Y. Lui, G. Li, S. C. Fu, Y. W. Lee, and K. M. Chan, "Isolation and characterization of multipotent rat tendon-derived stem cells," Tissue Engineering Part A, vol. 16, no. 5, pp. 1549-1558, 2010.

[24] A. Kobayashi, M. Kang, H. Okawa et al., "Oxidative stress sensor Keapl functions as an adaptor for Cul3-based E3 ligase to regulate proteasomal degradation of Nrf2," Molecular and Cellular Biology, vol. 24, no. 16, pp. 7130-7139, 2004.

[25] Q. Niu, L. Mu, S. Li, S. Xu, R. Ma, and S. Guo, "Proanthocyanidin protects human embryo hepatocytes from fluoride-induced oxidative stress by regulating iron metabolism," Biological Trace Element Research, vol. 169, no. 2, pp. 174-179, 2016.

[26] F. Ye, X. Li, and L. Li, "The role of Nrf2 in protection against $\mathrm{Pb}$ induced oxidative stress and apoptosis in SH-SY5Y cells," vol. 86, pp. 191-201, 2015.

[27] X. S. Zhang, S. Ha, X. L. Wang, Y. L. Shi, S. S. Duan, and Z. A. Li, "Tanshinone IIA protects dopaminergic neurons against 6-hydroxydopamine-induced neurotoxicity through miR-153/NF-E2-related factor 2/antioxidant response element signaling pathway," Neuroscience, vol. 303, pp. 489-502, 2015.

[28] J. Vriend and R. J. Reiter, “The Keap1-Nrf2-antioxidant response element pathway: a review of its regulation by melatonin and the proteasome," Molecular and Cellular Endocrinology, vol. 401, pp. 213-220, 2015. 

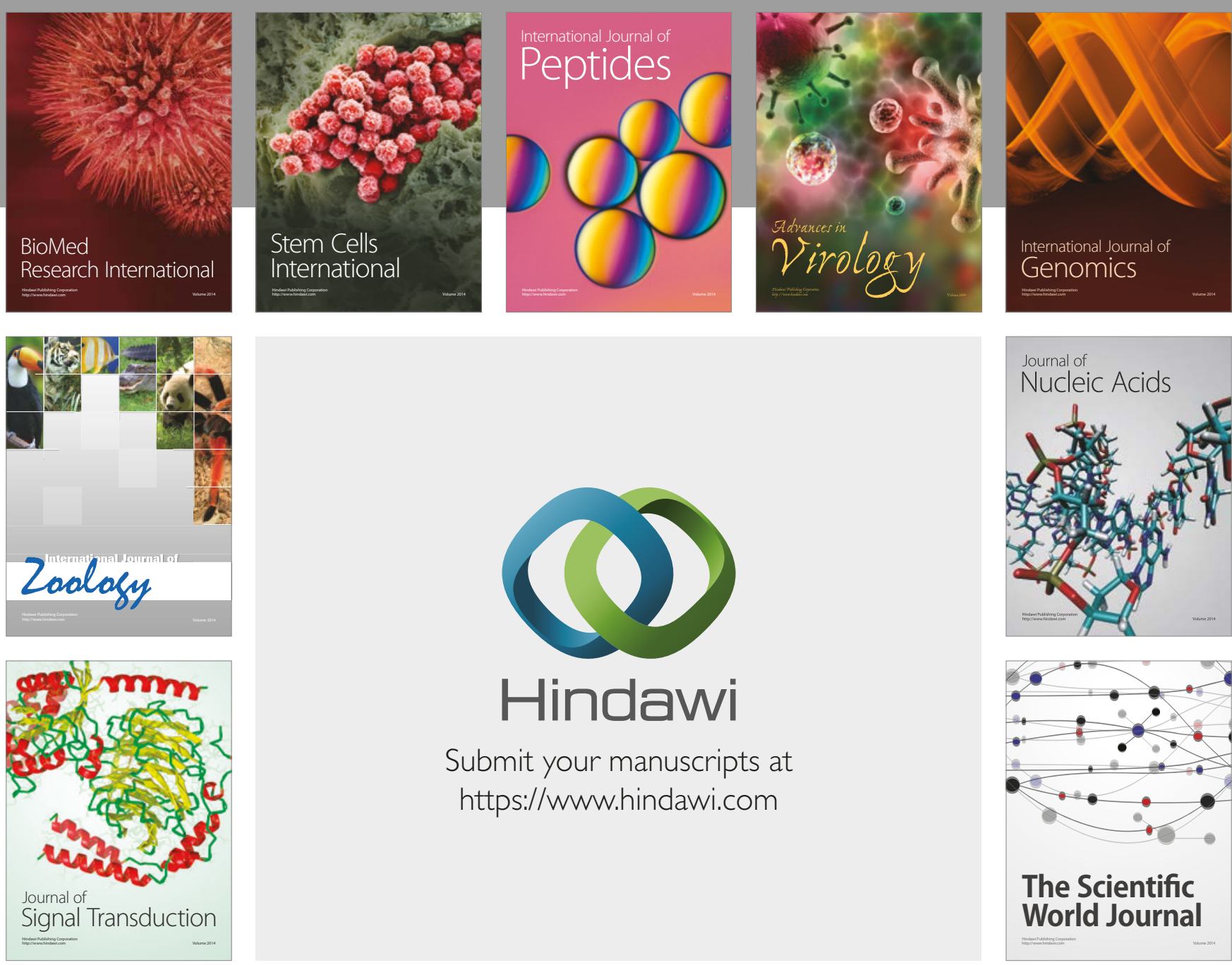

Submit your manuscripts at

https://www.hindawi.com
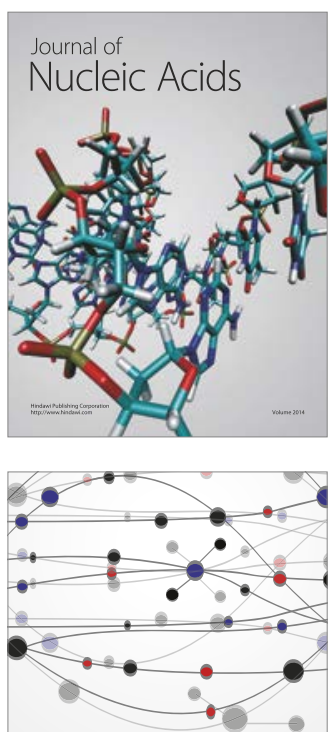

The Scientific World Journal

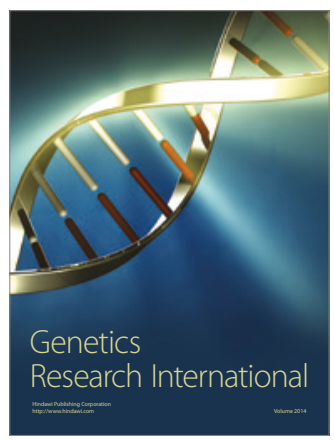

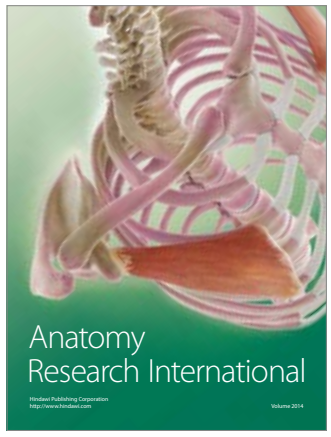

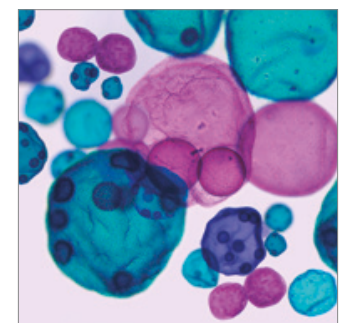

International Journal of Microbiology
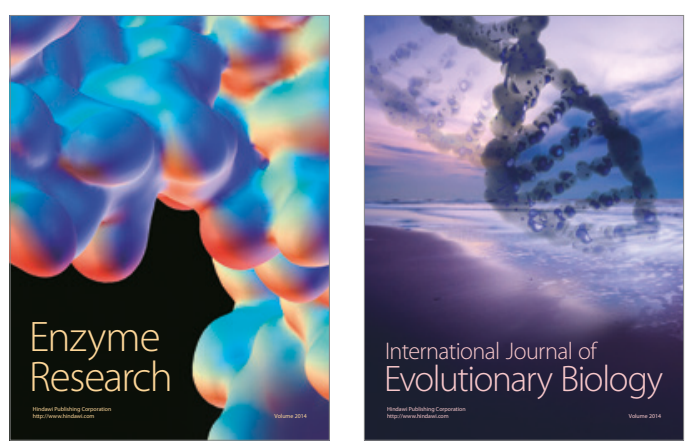
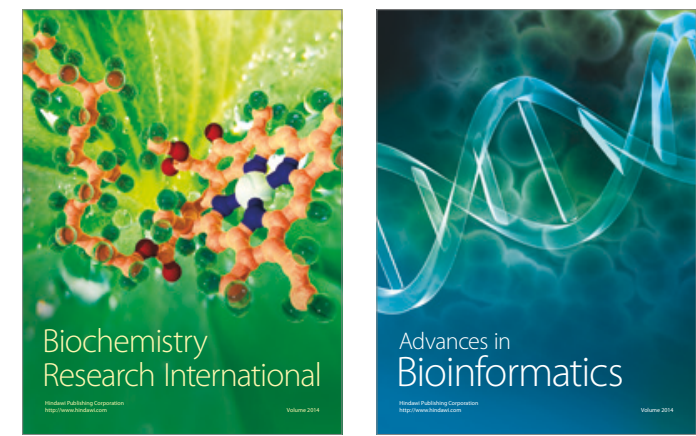

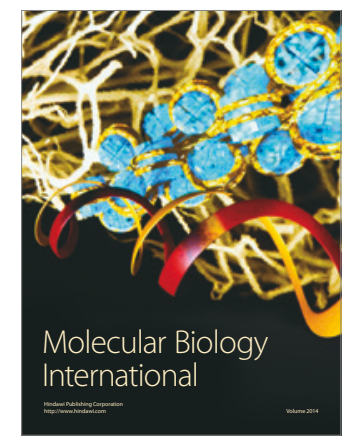

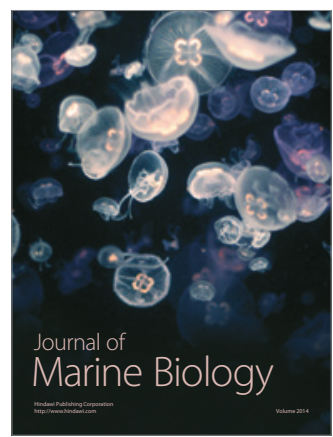

